\title{
Exploração normal, resistência normal
}

Quase invariavelmente destinadas à derrota e a um possível massacre, as grandes insurreições foram em geral demasiado desorganizadas para alcançar qualquer resultado duradouro. As pacientes e silenciosas lutas resolutamente levadas a cabo pelas comunidades rurais ao longo dos anos produziriam mais do que esses fogos de palha.

Marc Bloch, French rural history

Como escreveu certa vez o editor de Field and garden, para as pessoas comuns os grandes homens são sempre impopulares. As massas não os entendem, pensam que todas aquelas coisas são desnecessárias, até mesmo o heroísmo. O homem pequeno não dá a mínima para uma grande era. Tudo o que ele quer é vez por outra frequentar um bar e comer goulash no jantar. Naturalmente, um estadista se irrita com vagabundos como esses, quando sua tarefa é levar seu povo a fazer parte dos livros de história, pobre coitado. Para um grande homem as pessoas comuns são um fardo pesado. É como oferecer a Baloun, com seu grande apetite, uma pequena salsicha húngara para o jantar, que bem isso pode fazer! Eu nem quero escutar quando os mandachuvas se reunirem e começarem a se queixar de nós.

Schweyk, in Bertold Brecht, Schweyk in the second world war, cena 1

\section{A história não escrita de resistência}

A ideia para este estudo, bem como suas preocupações e métodos, originou-se de uma crescente insatisfação com grande parte dos trabalhos recentes - tanto os meus como os de outros - sobre o tema das rebeliões 
e revoluções camponesas. ${ }^{1}$ É notório que a desordenada atenção em larga escala que foi dada à insurreição camponesa, pelo menos na América do Norte, foi estimulada pela guerra do Vietnã e por algo como um envolvimento amoroso acadêmico de esquerda com as guerras de liberação nacional. Neste caso, o interesse e a fonte material se reforçavam mutuamente, pois os registros históricos e arquivísticos eram mais ricos precisamente naqueles momentos em que o campesinato representou uma ameaça ao Estado e à ordem internacional existente. Em outros momentos, o que significa a maior parte do tempo, os camponeses apareceram nos registros históricos não tanto como atores históricos, mas como contribuintes mais ou menos anônimos às estatísticas sobre recrutamento militar, impostos, migração de mão-de-obra, propriedade da terra, e produção agrícola.

O fato é que, apesar de toda a sua importância quando efetivamente ocorrem, as rebeliões camponesas, para não falar de "revoluções" camponesas, são poucas e temporalmente muito espaçadas. Não apenas são comparativamente raras as circunstâncias que favorecem levantes camponeses de larga escala, como, quando estes efetivamente ocorrem, as revoltas que eles desenvolvem são quase sempre esmagadas sem a menor cerimônia. Na verdade, mesmo uma revolta fracassada pode conquistar alguma coisa: algumas concessões por parte do Estado ou dos latifundiários, uma breve suspensão de novas e penosas relações de produção ${ }^{2}$ e, não menos importante, uma lembrança de resistência e coragem que pode ficar guardada para o futuro. Tais ganhos, entretanto, são incertos, ao passo que o massacre, a repressão e a desmoralização da derrota são bastante certos e reais. Merece ser lembrado também que, mesmo naqueles momentos históricos extraordinários em que uma revolução apoiada por camponeses de fato alcança a tomada do poder, os resultados são algo que, na melhor das hipóteses, envolve um misto de aspectos favoráveis e desfavoráveis para o campesinato. Seja o que mais for que a revolução possa conseguir, ela quase sempre cria um aparelho estatal mais coercitivo e hegemônico - que muitas vezes se beneficia da exploração da população rural como nenhum outro anteriormente. Muito frequentemente,

Do original "Normal exploitation, normal resistance", publicado como o segundo capítulo do livro Weapons of the weak: everyday forms of peasant resistance (New Haven: Yale University Press, 1985). Direitos autorais concedidos pela Yale Representation Ltd. Traduzido por André Villalobos. Ver, por exemplo, Moore Jr. (1966), Paige (1975), Wolf (1969, 1976), Popkin (1979).

Para um exemplo de tais ganhos temporários, ver o excelente estudo de Hobsbawm e Rudé (1968, p. 281-299). 
o campesinato se encontra na irônica posição de haver ajudado a fortalecer um grupo dirigente cujos planos relacionados à industrialização, à política tributária e à coletivização estão em conflito com os objetivos pelos quais os camponeses imaginavam estar lutando. ${ }^{3}$

Por todas essas razões, ocorreu-me que a ênfase sobre rebelião camponesa estava mal posta. Ao invés disso, pareceu-me muito mais importante aquilo que poderíamos chamar de formas cotidianas de resistência camponesa - a prosaica, mas constante, luta entre o campesinato e aqueles que procuram extrair-lhe trabalho, alimentos, impostos, rendas e juros. A maioria das formas assumidas por essa luta não chegam a ser exatamente a de uma confrontação coletiva. Tenho em mente, neste caso, as armas ordinárias dos grupos relativamente desprovidos de poder: relutância, dissimulação, falsa submissão, pequenos furtos, simulação de ignorância, difamação, provocação de incêndios, sabotagem, e assim por diante. Essas formas Brechtianas de luta de classe têm certas características em comum. Elas exigem pouca ou nenhuma coordenação; representam uma forma de autoajuda individual; e tipicamente evitam qualquer confrontação simbólica com a autoridade ou as normas da elite. Entender essas formas corriqueiras de resistência é entender o que grande parte do campesinato faz "entre revoltas" para defender seus interesses da melhor forma que conseguem fazê-lo.

Seria um grave equívoco, como o é no caso das rebeliões camponesas, romantizar abertamente as “armas dos fracos”. É improvável que elas façam mais do que afetar marginalmente as várias formas de exploração com que os camponeses se defrontam. Além disso, o campesinato não possui o monopólio sobre essas armas, como pode facilmente atestar qualquer pessoa que tenha observado autoridades e proprietários de terras resistindo e impedindo a continuidade de políticas estatais que lhes sejam desvantajosas.

Por outro lado, esses modos brechtianos de resistência não são triviais. A deserção e a fuga à conscrição e à corveia indubitavelmente limitaram as aspirações imperiais de muitos monarcas no Sudeste da Ásia ${ }^{4}$ ou, a esse respeito, na Europa. Esse processo e seu potencial impacto não são mais bem captados em qualquer outro texto do que no relato de R. C. Cobb sobre a resistência e a deserção ao recrutamento militar na França pós-revolucionária e durante o começo do Império:

Algumas dessas questões são examinadas em Scott (1979).

Ver os excelentes relatos e análises de Adas (1981). 
Do ano V ao ano VII, há cada vez mais relatos provenientes de uma variedade de Departamentos (...) de todos os conscritos de um dado cantão terem voltado para casa, estando aí vivendo sem serem molestados. Melhor ainda, muitos deles não voltaram para casa, pois nem chegaram a deixá-la (...). Também no ano VII, os dedos decepados das mãos direitas - a forma mais comum de mutilação - começam a testemunhar estatisticamente a força do que pode ser descrito como um vasto movimento de cumplicidade coletiva, envolvendo a família, a paróquia, as autoridades locais, cantões inteiros.

Nem mesmo o Império, com uma polícia rural vastamente mais numerosa e confiável, conseguiu, a não ser temporariamente, diminuir a velocidade da hemorragia que (...), a partir de 1812, novamente atingiu proporções catastróficas. Não poderia ter havido um referendum mais eloquente sobre a universal impopularidade de um regime opressivo; e não há um espetáculo mais encorajador para um historiador do que um povo que decidiu não mais lutar e que volta a casa sem espalhafato. (...) As pessoas comuns, pelo menos neste aspecto, tiveram clara participação na derrubada do mais pavoroso regime da França. (COBB, 1970, p. 96-97) ${ }^{5}$

O colapso do exército e da economia dos Confederados no curso da Guerra Civil nos Estados Unidos é outro exemplo do papel decisivo das defecções silenciosas e não declaradas. Estima-se que, ao todo, quase 250.000 brancos em condições de servir ao exército desertaram ou escaparam à conscrição. ${ }^{6}$ Como era de esperar, as razões parecem ter sido tanto morais como materiais. Os brancos pobres, especialmente os das terras de pastoreio não possuidores de escravos, ressentiam-se de lutar por uma instituição cujos principais beneficiários eram muitas vezes legalmente excluídos do serviço militar. ${ }^{7}$ Revezes militares e aquela que foi chamada a "crise de subsistência de 1862" induziram muitos a desertar e retornar para suas famílias em dificuldades. Nas próprias fazendas, a insuficiência de feitores brancos e a

\footnotetext{
Para um penetrante relato da automutilação para evitar a conscrição, ver Zola (1980).

6 Ver o excelente estudo de Armstead L. Robinson, Bitter fuits of bondage (a sair, caps. 5 e 6). [Scott indica o livro como tendo publicação próxima por Yale University Press. No entanto, o manuscrito sofreu contínuas revisões e só veio a ser publicado, postumamente, em 2005, por University of Virginia Press. N.E.]

Essa questão centrava-se na muito ressentida lei, conhecida como a "Lei dos Vinte Negros" ["TwentyNigger Law"], que estipulava que um branco em idade de servir o exército podia ser liberado do serviço militar caso fosse necessário para supervisionar vinte ou mais escravos. Essa lei, conjugada com a contratação de substitutos pelas famílias ricas, estimulou a difundida convicção de que essa era "uma guerra de homens ricos, mas uma luta de homens pobres" (ROBINSON, cap. 5).
} 
natural afinidade dos escravos com os objetivos do Norte deram ensejo à falta de empenho no trabalho e a fugas em escala massiva. Como na França, aqui também seria possível dizer que a Confederação foi liquidada por uma avalanche social de pequenos atos de insubordinação levados a efeito por uma improvável coalizão de escravos e pequenos proprietários rurais - uma coalizão sem nome, sem organização, sem liderança e, certamente, sem uma conspiração leninista por trás.

De modo similar, a sonegação e a evasão fiscal classicamente limitaram a ambição e o alcance dos Estados do Terceiro Mundo - seja o pré-colonial, o colonial, ou o independente. Como veremos, a coleta oficial do dízimo islâmico em arroz, em Sedaka, por exemplo, é apenas uma pequena fração do que é legalmente devido, graças a uma rede de cumplicidade e de embustes que mutila seu impacto. Não é de admirar que uma grande parte das receitas de impostos dos Estados do Terceiro Mundo seja coletada sob a forma de tributos sobre importações e exportações; esse padrão se deve em grande medida à capacidade de resistência de seus súditos ou cidadãos. Até mesmo uma leitura casual da literatura sobre "desenvolvimento" rural propicia uma rica colheita de esquemas e programas governamentais impopulares levados à extinção pela resistência passiva do campesinato. $\mathrm{O}$ autor de um raro relato detalhando como os camponeses - neste caso, na África oriental - conseguiram, ao longo de décadas, desfazer ou evadir políticas governamentais que os ameaçavam, conclui no seguinte tom:

Nesta situação, entende-se que a equação do desenvolvimento seja frequentemente reduzida a um jogo de soma zero. Como mostrou este estudo, os vencedores desses jogos não são sempre, de modo algum, os dirigentes. O camponês africano é dificilmente um herói, na perspectiva do pensamento corrente sobre desenvolvimento, mas ele frequentemente derrotou as autoridades por meio do uso de suas habilidades para enganar. (HYDEN, 1980, p. 231)

Em algumas ocasiões, essa resistência tornou-se ativa, mesmo violenta. Mais frequentemente, contudo, ela assume a forma do descumprimento passivo, da sutil sabotagem, da evasão e do engano. Os persistentes esforços do governo colonial em Malaia [Malásia Ocidental], no sentido de desencorajar o campesinato de produzir e vender borracha para não competir com as 
grandes plantações em termos de terras e mercados, constituem um exemplo disso. ${ }^{8}$ Vários esquemas restritivos e leis sobre o uso da terra foram tentados de 1922 a 1928, e novamente nos anos 1930, com resultados apenas modestos em virtude da resistência camponesa. Os esforços dos camponeses, em autointitulados Estados socialistas, no sentido de impedir e, depois, mitigar ou mesmo eliminar formas impopulares de agricultura coletiva representam um notável exemplo das técnicas defensivas disponíveis para um campesinato assediado. De novo, a luta é marcada menos por confrontações massivas e desafiadoras do que por uma evasão silenciosa que é igualmente massiva e frequentemente muito mais efetiva. ${ }^{9}$

O estilo de resistência em questão talvez seja mais bem descrito por meio de pares de formas contrastantes de resistência, cada qual dirigido a aproximadamente o mesmo objetivo. O primeiro elemento de cada par é a resistência "cotidiana", em nossa acepção do termo; o segundo representa o desafio aberto dominante no estudo da política do campesinato e da classe trabalhadora. Em uma esfera encontra-se, por exemplo, o processo silencioso e gradativo através do qual intrusos camponeses muitas vezes penetraram e se estabeleceram em terras de grandes propriedades rurais e terras de floresta de propriedade estatal. Em outra, uma notória invasão de terras contestando abertamente as relações de propriedade. Em termos de ocupação e uso efetivos, esse tipo de penetração pode realizar mais do que uma invasão abertamente desafiadora, embora a distribuição de jure da propriedade da terra não seja nunca publicamente contestada. Passando a outro exemplo, em uma esfera encontram-se as deserções militares que incapacitam um exército e, em outra, um motim aberto destinado a eliminar ou substituir oficiais. Como assinalamos, onde os motins podem fracassar, as deserções podem alcançar alguma coisa precisamente porque visam antes a autoajuda e o afastamento do que a confrontação institucional. E, ademais, furtar-se à aquiescência é em certo sentido mais radical, em suas implicações para o exército como instituição, do que a substituição dos oficiais. Um último

8 O melhor e mais completo balanço sobre o assunto pode ser encontrado em Ghee (1977). Ver também uma argumentação persuasiva em Nonini, Diener e Robkin (1979).

9 Para um cuidadoso e fascinante relato sobre as maneiras pelas quais, na China, as equipes e brigadas de produção puderam, até 1978, ter alguma influência na definição do "excedente" de cereais que tinha de ser vendido ao Estado, ver Oi (1983). Praticamente toda essa resistência era chamada de "oposição branda" pelos que a praticavam, os quais deixavam claro que ela só era bem sucedida se se mantivesse uma "manifestação aparente" de aquiescência (OI, 1983, p. 238). 
exemplo: em uma esfera está o furto em depósitos públicos ou privados de cereais; na outra, o ataque ostensivo a mercados e armazéns objetivando uma aberta redistribuição do estoque de alimentos.

O que as formas cotidianas de resistência compartilham com as confrontações públicas mais dramáticas é, naturalmente, o fato de serem voltadas a mitigar ou rejeitar demandas feitas pelas classes superiores ou a levar adiante reivindicações com relação a tais classes. Essas demandas e reivindicações têm normalmente a ver com o nexo material da luta de classes - a apropriação da terra, do trabalho, dos impostos, das rendas, e assim por diante. Onde a resistência cotidiana se distingue mais evidentemente de outras formas de resistência é em sua implícita negação de objetivos públicos e simbólicos. Enquanto a política institucionalizada é formal, ostensiva, preocupada com a mudança sistemática e de jure, a resistência cotidiana é informal, muitas vezes dissimulada, e em grande medida preocupada com ganhos de facto imediatos. ${ }^{10}$

É razoavelmente claro que, frequentemente, o sucesso da resistência de facto é diretamente proporcional à conformidade simbólica com que é dissimulada. A insubordinação ostensiva provocará, em praticamente qualquer contexto, uma resposta mais rápida e feroz do que uma insubordinação que pode ser tão penetrante, mas nunca se aventure a contestar as definições formais de hierarquia e poder. Para a maioria das classes subalternas que, de fato, tiveram historicamente escassas possibilidades de melhorar seu status, essa forma de resistência foi a única opção. O que pode ser realizado no interior dessa camisa de força simbólica é, não obstante, até certo ponto, um testemunho da persistência e inventividade humana, como ilustra este relato sobre a resistência das castas inferiores na Índia:

Empregados presos a um vínculo vitalício de trabalho [lifelong indentured servants] caracteristicamente expressavam descontentamento quanto a sua relação com seus patrões através do desempenho descuidado e ineficiente de seu trabalho. Intencional ou

\footnotetext{
${ }^{10}$ Há aqui um interessante paralelo com parte da literatura feminista sobre a sociedade camponesa. Em muitas, embora não todas, sociedades camponesas, os homens provavelmente dominam todo exercício formal e ostensivo do poder. Ocasionalmente se afirma que as mulheres podem exercer considerável poder na medida em que não desafiem abertamente o mito formal da dominância masculina. Em outras palavras, ganhos "reais"são possíveis contanto que a ordem simbólica mais ampla não seja posta em questão. De modo bastante semelhante, pode-se sustentar que o campesinato muitas vezes acha taticamente conveniente, bem como necessário, deixar intacta a ordem formal enquanto dirige sua atenção a objetivos políticos que podem não ter nunca um reconhecimento formal. Para uma argumentação feminista de teor semelhante, ver Rogers (1975).
} 
inconscientemente, eles podiam fingir doença, ignorância ou incompetência, criando transtornos para os patrões. Muito embora o patrão pudesse retaliar, recusando-se a conceder benefícios adicionais ao empregado, ele continuava obrigado a mantê-lo em um nível de subsistência para não perder inteiramente seu investimento. Desde que não se expressasse como uma contestação ostensiva, esse método de resistência passiva era quase imbatível; ele reforçava o estereótipo dos Havics a respeito do caráter das pessoas de casta inferior, mas lhes dava pouco recurso para agir. (HARPER, 1968, p. 48-49; ênfases minhas)

Tais formas de resistência pertinaz estão especialmente bem documentadas na vasta literatura sobre a escravidão nos Estados Unidos, onde a contestação ostensiva era normalmente temerária. A história da resistência à escravidão no Sul de antes da Guerra Civil é, em grande medida, uma história de corpo mole, falsa aquiescência, fuga, fingimento de ignorância, sabotagem, roubo e, não menos importante, resistência cultural. Essas práticas raramente ou nunca puseram em questão o sistema escravocrata enquanto tal, não obstante conseguiram muito mais com seu modo não declarado, limitado e sem truculências, do que os poucos heroicos e breves levantes armados sobre os quais muito se escreveu. Os próprios escravos parecem ter compreendido que, na maioria das circunstâncias, sua resistência só poderia ser bem-sucedida na medida em que se ocultasse atrás da máscara da submissão. É possível imaginar os pais dando aos filhos conselhos não muito diferentes daqueles que, aparentemente, ouvem de seus pais os trabalhadores assalariados contemporâneos das fazendas da Indonésia:

Eu digo a eles [aos jovens]: lembrem-se, vocês estão vendendo seu trabalho e quem o compra quer ver que ele lhe renda alguma coisa; portanto, trabalhem quando ele estiver por perto, vocês podem relaxar depois, quando ele for embora; mas certifiquem-se de sempre parecer estar trabalhando quando os inspetores lá estiverem. (STOLER, 1985, p. 184)

Duas observações específicas surgem desta perspectiva. A primeira é a de que a natureza da resistência é grandemente influenciada pelas formas existentes de controle do trabalho e pelas crenças a respeito da probabilidade e severidade da retaliação. Onde as consequências de uma greve aberta forem provavelmente catastróficas em termos de demissão ou prisão, a força de trabalho pode recorrer a uma operação tartaruga [slowdown] ou a 
um desempenho de baixa qualidade no emprego. A natureza dessas ações, muitas vezes não declaradas e anônimas, torna particularmente difícil ao antagonista avaliar a culpa e aplicar sanções. Na indústria, a operação tartaruga veio a ser chamada de greve "italiana" e que é utilizada particularmente quando se teme repressão, como na Polônia sob lei marcial, em 1983. ${ }^{11}$ Naturalmente, o pagamento por peça produzida foi muitas vezes usado como um meio de frustrar formas de resistência acessíveis aos trabalhadores pagos por hora ou dia de trabalho. Onde prevalece o pagamento por peça, como ocorreu com as tecelagens de seda ou algodão na Alemanha do século XIX, é provável que a resistência encontre expressão não nas operações tartaruga, o que seria contra os próprios interesses dos trabalhadores, mas em formas tais como "diminuição do peso do tecido acabado, acabamento imperfeito, e furto de materiais" (LINEBAUGH, 1976, p. 10) ${ }^{12}$ Cada forma de controle ou pagamento do trabalho provavelmente gera, mantidas as demais circunstâncias, suas próprias formas características de resistência silenciosa e "contra-apropriação".

A segunda observação é a de que a resistência não é dirigida necessariamente à fonte imediata de apropriação. Na medida em que o objetivo dos resistentes é tipicamente satisfazer necessidades prementes como segurança física, alimento, terra, ou renda, e fazê-lo em relativa segurança, eles podem simplesmente seguir a linha de menor resistência. Os camponeses e proletários prussianos na década de 1830, pressionados por suas acanhadas propriedades e salários abaixo do nível de subsistência, responderam pela emigração e pela invasão furtiva de propriedade alheia [poaching] em busca de madeira, forragem e caça em larga escala. O ritmo do "crime florestal" aumentava à medida que os salários declinavam, as provisões encareciam, e onde a emigração era mais difícil; em 1836, houve a instauração de 207.000 protestos na Prússia, 150.000 dos quais por crimes florestais (LINEBAU$\mathrm{GH}, 1976$, p. 13). ${ }^{13}$ Os invasores eram apoiados por um ânimo popular de

11 Ver, por exemplo, o New York Times de 18 de agosto de 1983, p. A6,"Polish underground backs call for slowdown", no qual é observado que "a tática de uma operação tartaruga, conhecida na Polônia como uma greve italiana, foi usada no passado pelos trabalhadores porque ela reduz o risco de represália".

12 Ver também a brilhante análise do trabalhador-poeta húngaro, Haraszti (1978), sobre o trabalho pago por peça.

13 Em Baden, em 1842, houve uma condenação por crimes desse tipo para cada quatro habitantes. Durante três séculos, as invasões furtivas de propriedade alheia [poaching] foram o crime mais comum na Inglaterra, e constituíram a matéria de grande parte da legislação repressiva. Ver, por exemplo, as seleções feitas por Hay e Thompson (1975). 
cumplicidade originado por uma tradição anterior de livre acesso à floresta, mas eles agora pouco se importavam se os coelhos ou a madeira de que se apropriavam provinham da terra de seu empregador ou senhorio. Assim, a reação a uma apropriação em uma esfera pode conduzir suas vítimas a explorar pequenas aberturas, disponíveis alhures, que se sejam mais acessíveis e menos perigosas. ${ }^{14}$

Tais técnicas de resistência são bem adaptadas às características particulares do campesinato. Sendo uma classe diversificada e de baixo teor "classista" propriamente dito ["low classness"], espalhada pelo campo, frequentemente carente da disciplina e liderança que poderia estimular uma oposição de tipo mais organizado, o campesinato se afina melhor com extensas campanhas de desgaste no estilo de guerrilha, que requerem pouca ou nenhuma coordenação. Suas ações individuais de redução do ritmo de atividade ou de evasão são muitas vezes reforçadas por uma venerável cultura popular de resistência. Vistas à luz de uma subcultura que as apoia e do conhecimento de que o risco para qualquer resistente singular é geralmente reduzido na medida em que toda a comunidade esteja envolvida, é plausível que as consideremos um movimento social. Curiosamente, no entanto, trata-se de um movimento social sem organização formal, sem líderes formais, sem manifestos, sem obrigações, sem nome e sem bandeira. Em virtude de sua invisibilidade institucional, as atividades que não cheguem a se caracterizar por uma escala massiva, caso sejam notadas, raramente são consideradas socialmente significativas.

Multiplicados por muitos milhares de vezes, tais pequenos atos de resistência dos camponeses podem, no final das contas, desorganizar completamente as políticas sonhadas por seus supostos superiores na capital. O Estado pode responder de diversas maneiras. As políticas podem ser remodeladas segundo expectativas mais realistas. Podem ser mantidas, mas reforçadas por incentivos positivos voltados a estimular a aquiescência e conformidade voluntárias. E, naturalmente, o Estado pode simplesmente optar por empregar mais coerção. Qualquer que seja a resposta, precisamos não perder de vista o fato de que a ação do campesinato transformou ou estreitou, desse modo, as opções de

\footnotetext{
${ }_{14}$ Aparentemente, o roubo de madeira na Alemanha nesse período raramente atingiu as florestas comunais. Nem é preciso dizer que, quando um pobre sobrevive apropriando-se de pertences de outros na mesma situação, não se pode falar de resistência. Uma questão central a respeito de qualquer classe subordinada é a medida em que ela pode, por meio de sanções internas, evitar a competição "antropofágica" entre seus membros, a qual só pode servir aos interesses das classes apropriadoras.
} 
política disponíveis para o Estado. É dessa maneira, e não através de revoltas, para não falar de pressão política legal, que o campesinato classicamente fez sentir a sua presença política. Assim, qualquer história ou teoria da política camponesa que procure fazer justiça ao campesinato como ator histórico precisa necessariamente lidar com o que chamei formas cotidianas de resistência. Por essa razão é importante tanto documentar como trazer alguma ordem conceitual a essa aparente confusão de atividade humana.

Formas cotidianas de resistência não proporcionam manchetes jornalísticas. ${ }^{15}$ Da mesma forma que milhões de polipoides antozoários criam, sem planejamento e organização [willy-nilly], um recife de coral, assim também milhares e milhares de atos individuais de insubordinação e evasão criam sua própria barreira de recife econômica ou política. Raramente há uma confrontação dramática, qualquer momento particularmente digno de virar notícia. E sempre que, para prosseguir com a analogia, o navio do Estado encalha nessa barreira de recife, a atenção é dirigida tipicamente para o acidente em si e não para o vasto agregado de pequenos atos que o tornaram possível. Só raramente os perpetradores desses pequenos atos buscam chamar a atenção sobre si mesmos. Sua segurança repousa no anonimato. Também é extremamente raro que as autoridades estatais queiram dar publicidade à insubordinação. Fazê-lo seria admitir que sua política é impopular e, sobretudo, expor a debilidade de sua autoridade no campo - e nenhuma das duas coisas é do interesse do Estado soberano. ${ }^{16}$ A natureza dos atos em si e o mutismo dos antagonistas conspira, desse modo, para criar uma espécie de silêncio de cumplicidade que faz com que as formas cotidianas de resistência não apareçam nos registros históricos.

A história e a ciência social, por serem escritas por uma intelectualidade que se utiliza de registros escritos, também criados em grande medida por autoridades letradas, simplesmente não estão bem equipadas para revelar as

15 Como assinalam Hobsbawm e Rudé (1968), não foram apenas as elites conservadoras que negligenciaram essa forma de resistência, mas também a esquerda urbana: "Os historiadores dos movimentos sociais parecem ter reagido de forma muito semelhante à do resto da esquerda urbana - à qual a maioria deles tradicionalmente pertenceu -, isto é, tenderam a não tomar consciência dela a menos que aparecesse em uma forma suficientemente dramática ou em escala suficientemente grande para ser notada pelos jornais citadinos".

${ }^{16}$ Mas não inteiramente. É provável que registros distritais se mostrem gratificantes a esse respeito, quando as autoridades distritais tentam explicar a seus superiores na capital o fato de não terem sido atingidos os objetivos, digamos, na coleta de impostos ou nos números referentes ao recrutamento militar. Imagina-se também que sejam abundantes os registros informais e orais, como, por exemplo, nas reuniões informais dos gabinetes ou ministérios convocadas para lidar com insucessos de políticas causados por insubordinação rural. 
formas silenciosas e anônimas de luta de classe que tipificam o campesinato. ${ }^{17}$ Seus praticantes aderem implicitamente à conspiração dos participantes que atuam, eles próprios, como se houvessem jurado manter segredo. Coletivamente, esse improvável conluio contribui para um estereótipo, conservado tanto na literatura como na história, do campesinato como uma classe que se alterna entre longos períodos de abjeta passividade e breves, violentos e fúteis explosões de fúria.

Ele tinha atrás de si séculos de medo e submissão, seus ombros haviam se tornado insensíveis aos golpes, sua alma tão oprimida que ele não reconhecia sua própria degradação. Você poderia espancá-lo, deixá-lo à mingua, despojá-lo de tudo, ano após ano, antes que ele viesse a abandonar sua cautela e estupidez, com sua mente cheia toda sorte de ideias confusas que ele não conseguia entender direito; e isso continuou até que um ápice de injustiça e sofrimento arremessou-o à garganta de seu senhor como um animal doméstico enfurecido que houvesse sido submetido a muitos atos de crueldade. (ZOLA, 1980, p. 91)

Há um grão de verdade na visão de Zola, mas apenas um grão. É verdade que o comportamento "em cena" dos camponeses durante tempos de tranquilidade oferece uma imagem de submissão, medo e cautela. Por contraste, as insurreições camponesas parecem reações viscerais de uma fúria cega. $\mathrm{O}$ que falta na descrição dessa passividade "normal" é a lenta, desgastante e silenciosa luta sobre rendas, colheitas, trabalho e impostos, na qual submissão e estupidez muitas vezes não são mais que uma pose - uma tática necessária. O que falta nesse quadro das explosões periódicas é a visão subjacente de justiça que os informa e seus objetivos e alvos específicos, que frequentemente são de fato bastante racionais. ${ }^{18}$ As próprias explosões são muitas vezes um sinal de que as formas normais e em grande medida encobertas de luta de classes estão malogrando ou atingiram um momento de crise. Tais declarações de guerra aberta, com seus riscos mortais, normalmente só ocorrem depois de uma luta prolongada em um terreno diferente.

\footnotetext{
${ }^{17}$ As exceções parciais que vêm à mente são a antropologia, por sua insistência na observação direta no campo, e a história da escravidão e da coletivização soviética.

18 Não quero, de modo algum, sugerir que a violência decorrente de vingança, ódio e fúria não tenha papel algum - apenas que não exaure completamente o assunto, como sugerem Zola e outros. É certamente verdadeiro, como afirma Cobb (1970, p. 89-90), que Rudé (1964) foi longe demais ao transformar revoltosos em atores políticos sóbrios, domesticados, burgueses.
} 


\section{Resistência como pensamento e símbolo}

Até aqui, tratei as formas cotidianas de resistência camponesa como se elas não fossem muito mais do que uma coleção de ações ou comportamentos individuais. Confinar a análise ao comportamento apenas é, contudo, deixar escapar grande parte do assunto. Isso reduz a explicação da ação humana ao nível que poderia ser usado para explicar como o búfalo domesticado das regiões pantanosas resiste ao seu condutor para estabelecer um ritmo de trabalho tolerável ou porque o cachorro rouba restos de comida da mesa. Mas, como estou procurando entender a resistência de seres sociais pensantes, dificilmente posso ignorar sua consciência - o significado que eles atribuem a seus atos. Os símbolos, as normas, as formas ideológicas que eles criam constituem o pano de fundo indispensável para o seu comportamento. Por parcial ou imperfeito que seja seu entendimento da situação, eles são dotados de intenções, valores e intencionalidades que condicionam suas ações. Isso é tão evidente que dificilmente mereceria ser reafirmado não fosse pela lamentável tendência, nas ciências comportamentais, de inferir o comportamento de massa diretamente dos sumários estatísticos sobre renda, ingestão de calorias, circulação de jornais ou propriedade de estações de rádio. Por conseguinte, busco não somente expor e descrever os padrões de resistência cotidiana como um comportamento distinto com implicações de longo alcance, mas também fundamentar essa descrição em uma análise dos conflitos de significado e valor em que surgem esses padrões e para os quais eles contribuem.

A relação entre pensamento e ação é, para dizê-lo de forma bastante singela, uma questão complicada. Aqui, sem maiores rodeios, desejo enfatizar apenas dois pontos. Em primeiro lugar, nem intenções nem atos são "causas primeiras". Atos nascidos de intenções retroagem, como que em círculo, influenciando a consciência e, consequentemente, as intenções e atos subsequentes. Assim, atos de resistência e pensamentos sobre a resistência (ou sobre seu significado) estão em constante comunicação - em constante diálogo. Em segundo lugar, as intenções e a consciência não estão ligadas ao mundo material da mesma forma que o comportamento. É possível e usual que os atores humanos concebam uma linha de ação que, no momento, seja impraticável ou impossível. Assim, uma pessoa pode sonhar com uma vingança ou com um milenar reino de justiça que pode nunca vir a ocorrer. Por outro lado, conforme mudem as circunstâncias, pode ser que venha a tornar-se possível agir a partir desses sonhos. $\mathrm{O}$ domínio da consciência nos dá uma espécie de acesso privilegiado a linhas de 
ação que podem - somente podem - tornar-se plausíveis em algum momento futuro. Como, por exemplo, dar uma explanação adequada de qualquer rebelião camponesa sem algum conhecimento sobre os valores compartilhados, as conversas de bastidores, a consciência do campesinato prévia à rebelião? ${ }^{19}$. Como, finalmente, entender as formas cotidianas de resistência sem referência às intenções, ideias e linguagem dos seres humanos que a praticam?

O estudo da consciência social das classes subordinadas é importante ainda por outra razão. Ele nos permite elucidar um debate importante tanto na literatura marxista como na não marxista - um debate centrado na proporção em que as elites são capazes de impor sua própria imagem de uma ordem social justa, não simplesmente sobre o comportamento das não-elites, mas também sobre sua própria consciência.

O problema pode ser expresso de maneira simples. Suponhamos que se possa estabelecer que um dado grupo é explorado e, além disso, que essa exploração ocorre em um contexto no qual a força coercitiva à disposição das elites e/ou do Estado torna virtualmente impossível qualquer manifestação ostensiva de descontentamento. Supondo também, para fins de argumentação, que o único comportamento observável é aparentemente de aquiescência, são possíveis pelo menos duas interpretações divergentes desse estado de coisas. Uma delas pode sustentar que, em virtude de uma ideologia religiosa ou social hegemônica, o grupo explorado efetivamente aceita sua situação como uma normal e mesmo justificável parte da ordem social. Essa explicação da passividade supõe pelo menos uma aceitação fatalista da ordem social e talvez até mesmo uma cumplicidade ativa - as quais seriam chamadas pelos marxistas de "mistificação" ou "falsa consciência". ${ }^{20}$ Ela se apoia tipicamente na suposição de que as elites dominam não apenas os meios físicos de produção, mas também os meios simbólicos de produção ${ }^{21}-$ e de

\footnotetext{
19 Para que isso não pareça, implícita e unilateralmente, tratar a consciência como anterior e em algum sentido causadora do comportamento, pode-se voltar um passo atrás e questionar sobre a construção dessa consciência. Uma investigação desse tipo começaria necessariamente com os dados sociais da posição do ator na sociedade. O ser social condiciona a consciência social.

${ }^{20}$ Ver a argumentação nesse sentido de Hoggart (1954, p. 77-78).

${ }^{21}$ Na tradição marxista, pode-se mencionar especialmente Antonio Gramsci (1971, p. 123-209); e Lukacs (1971). Ao que eu conheça, Marx nunca usou a expressão "falsa consciência", conquanto "o fetichismo da mercadoria" possa ser assim interpretado. Contudo, o fetichismo da mercadoria mistifica especialmente a burguesia, não meramente as classes subordinadas. Para uma visão crítica da "hegemonia" tal como possa aplicar-se ao campesinato, ver Scott (1977, p. 267-296), bem como o capítulo 7 de Weapons of the weak [no qual o presente artigo corresponde ao capítulo 2, N.E.].
} 
que essa hegemonia simbólica lhes possibilita controlar os próprios padrões pelos quais sua dominação é avaliada. ${ }^{22}$ Como disse Gramsci, as elites controlam os "setores ideológicos" da sociedade - cultura, religião, educação, e meios de comunicação - e podem, por isso, engendrar a aquiescência a sua dominação. Criando e disseminando um universo de discurso e os conceitos que o acompanham, definindo os padrões do que é considerado verdadeiro, belo, moral, justo, e legítimo, elas impedem que as classes subordinadas pensem livremente a seu modo. De fato, para Gramsci, o proletariado está mais escravizado no âmbito das ideias do que no do comportamento. A tarefa histórica do "partido" é, portanto, menos a de conduzir à revolução do que a de quebrar o miasma simbólico que bloqueia o pensamento revolucionário. Tais interpretações têm sido evocadas para dar conta da aquiescência das classes subordinadas, particularmente nas sociedades rurais como a Índia, onde um venerável sistema de rígida estratificação de castas é reforçado por sanções religiosas. Diz-se que as castas inferiores aceitam seu destino na hierarquia hindu na esperança de serem recompensadas na próxima vida. ${ }^{23}$

Uma interpretação alternativa dessa quietude poderia ser a de que ela se explica pelas relações de força no campo, e não pelos valores e crenças dos camponeses. ${ }^{24}$ Nessa perspectiva, a paz agrária pode mais propriamente ser a paz da repressão (recordada e/ou prevista) do que a do consentimento ou cumplicidade.

As questões colocadas por essas interpretações divergentes são centrais para a análise da política camponesa e para o estudo das relações de classes em geral. Grande parte desse debate ocorreu como se a escolha da interpretação fosse mais um assunto de preferência ideológica do analista do que de uma matéria de pesquisa efetiva. Sem subestimar os problemas envolvidos, creio haver diversas maneiras pelas quais se pode tratar empiricamente a questão. Em outras palavras, é possível dizer algo significativo sobre o peso relativo da consciência, por um lado, e da repressão (na verdade, lembrada ou potencial), por outro, no que diz respeito à contenção dos atos de resistência.

\footnotetext{
22 Para outras explanações sobre o mesmo fenômeno, ver, por exemplo, Parkin (1971, p. 79-102) e Dumont (1970).

${ }^{23}$ Observem-se, entretanto, os esforços das castas inferiores para elevar seu status ritual e, mais recentemente, a tendência dos harijans [intocáveis] de abandonar completamente o hinduísmo e converter-se ao islamismo, o qual não faz nenhuma distinção de casta entre os crentes.

${ }^{24}$ Ver, por exemplo, Huizer (1972).
} 
O argumento favorável à falsa consciência depende, afinal de contas, do alinhamento simbólico dos valores da elite e das classes subordinadas - isto é, no suposto de que o campesinato (proletariado) efetivamente aceita a maior parte da visão da elite sobre a ordem social. O que significa mistificação, se não o assentimento de um grupo com relação à ideologia que justifica sua exploração? Na medida em que a perspectiva de um grupo explorado está em substancial alinhamento simbólico com os valores da elite, o argumento a favor da mistificação se fortalece; na medida em que tal perspectiva contém valores desviantes e contraditórios, o argumento se enfraquece. Um estudo rigoroso da subcultura de um grupo subordinado e sua relação com os valores da elite dominante deveria nos dar parte da resposta que procuramos. Raramente as evidências serão inequívocas, pois a perspectiva de qualquer grupo conterá certa quantidade de correntes diversas e mesmo contraditórias. O que é notável não é a mera existência de temas subculturais desviantes, pois estes são praticamente universais, mas antes as formas que eles podem assumir, os valores que incorporam, e a atração emocional que inspiram. Assim, mesmo na ausência de resistência, não nos faltam recursos para tratar da questão da falsa consciência.

Para abrandar a natureza um tanto abstrata da argumentação desenvolvida até agora, pode ser útil ilustrar o tipo de evidência que pode estar relacionada diretamente com essa questão. Suponha, por exemplo, que o termo linguístico ostensivo para meação ou arrendamento seja um termo que enfatize sua equidade e justiça. Suponha, ademais, que o termo usado pelos arrendatários, pelas costas dos proprietários, para descrever essa relação seja muito diferente - cínico e jocoso. ${ }^{25}$ Não seria isso uma evidência plausível de que a visão do arrendatário a respeito dessa relação é em grande medida desmistificada - que ele não aceita pelo valor de face a definição de arrendamento posta pela elite? Quando Haji Ayub e Haji Kadir são chamados, pelas costas, de Haji “Vassoura", Haji Kedikut, ou Pak Ceti, não seria isso uma evidência plausível de que seu direito à terra, juros, rendimentos e respeito é pelo menos contestado no plano da consciência, quando não no terreno de ações ostensivas? O que pensar das seitas religiosas de classe baixa (os Quakers na Inglaterra do século XVII, os Saministas em Java no século XX, para citar apenas duas entre muitas) que abandonam o uso formas honoríficas

${ }_{25} \mathrm{O}$ arrendamento na região central de Luzon, nas Filipinas, é um caso notável a esse respeito. Comunicação de Benedick Kerkvliet, Universidade do Havaí. 
no tratamento aos socialmente superiores, insistindo, ao invés, em formas de tratamento mais prosaicas ou em usar palavras como "amigo" ou "irmão" para descrever todo mundo. Não seria isso uma evidência reveladora de que o libreto da elite para a hierarquia de nobreza e respeito no mínimo não é cantado ao pé da letra por seus súditos?

Por referência à cultura que os camponeses moldam a partir de sua experiência - seus comentários e conversação "nos bastidores", seus provérbios, canções folclóricas, sua história, lendas, chistes, linguagem, ritual, e religião - deve ser possível determinar em que medida e de que maneiras os camponeses de fato aceitam a ordem social propagada pelas elites. Alguns elementos da cultura das classes subalternas são, naturalmente, mais relevantes que outros no que toca a esta questão. Para qualquer sistema agrário, pode-se identificar um conjunto de valores-chave que justificam o direito a deferência, terra, impostos e renda, reivindicado por uma elite. É, em grande medida, matéria empírica saber-se se esses valores-chave encontram apoio ou oposição no interior da subcultura das classes subordinadas. Se bandidos ou aqueles que caçam em terras alheias são considerados heróis, podemos inferir que as transgressões aos códigos da elite evocam uma admiração vicária. Se as formas exteriorizadas de deferência são objeto de zombaria no plano privado, isso sugere que dificilmente se podem considerar os camponeses como aferrados a uma ordem social naturalmente ordenada. Se aqueles que procuram buscar o favor pessoal das elites são evitados e repelidos por outros de sua classe, temos uma evidência de que existe uma subcultura de classe subalterna com poder de sanção. A rejeição dos valores da elite, no entanto, é raramente uma proposição que se aplique de forma igual à totalidade desses valores, e apenas um estudo mais detido dos valores camponeses pode definir os pontos principais de fricção e de correspondência. Nesse sentido, pontos de fricção só se tornam sintomas relevantes quando se centram em valores-chave da ordem social, e quando se ampliam e se tornam mais duros.

\section{A experiência e a consciência dos agentes humanos}

Foi com essas questões em mente que passei mais de um ano e meio na aldeia de Sedaka, ouvindo, fazendo perguntas, e tentando entender as questões que animavam os aldeãos durante minha estada entre eles. $\mathrm{O}$ resultado, espero, é uma descrição bem fundamentada e detalhada das relações de classe em uma localidade muito pequena (setenta famílias, 360 
pessoas) que experimenta grandes mudanças (a "revolução verde": neste caso, a dupla safra de arroz). Grande parte dessa descrição, conquanto não toda, é um relato do que parece ser uma luta de classes perdedora contra o desenvolvimento agrícola capitalista e seus agentes humanos. Nem é preciso dizer que considerei importante ouvir cuidadosamente os agentes humanos que estava estudando, sua experiência, suas categorias, seus valores, seu entendimento da situação. Há várias razões para introduzir essa abordagem fenomenológica neste estudo.

A primeira razão tem a ver com a maneira pela qual pode e deve ser conduzida a ciência social. Em algumas variantes mais estruturalistas do neomarxismo, está na moda supor que, em qualquer país não socialista de Terceiro Mundo, a natureza das relações de classe pode ser inferida diretamente de umas poucas características diagnósticas - o modo de produção dominante, o modo e o ritmo de inserção na economia mundial, ou o modo de apropriação do excedente. Esse procedimento acarreta um salto direto, reducionista, de um ou poucos dados econômicos para a situação de classe presumida como decorrente desses dados. Não há quaisquer atores humanos, nesse caso, apenas mecanismos e marionetes. Por certo que os dados econômicos são cruciais; eles definem muito, mas não tudo, na situação com que se defrontam os atores humanos; limitam as respostas possíveis, imagináveis. Mas esses limites são muito amplos e, dentro deles, os atores humanos elaboram sua própria resposta, sua experiência de classe, sua própria história. Como observa E. P. Thompson em sua polêmica contra Althusser:

(...) nem é perdoável em um marxista [a recusa epistemológica da experiência], posto que a experiência é um termo intermediário necessário entre o ser social e a consciência social: é a experiência (muitas vezes a experiência de classe) que dá uma coloração à cultura, aos valores, e ao pensamento; é por meio da experiência que o modo de produção exerce uma pressão determinante sobre outras atividades. (...) As classes surgem porque homens e mulheres, em determinadas relações de produção, identificam seus interesses antagônicos e vêm a lutar, pensar e valorar de maneira classista; assim, o processo de formação de classe é um processo de autoconstrução, embora sob condições que são dadas. (THOMPSON, 1978, p. 98; 106-107)

De que outra forma pode um modo de produção afetar a natureza das relações de classe, a não ser mediado pela experiência e interpretação humanas? Somente captando essa experiência em algo que se aproxime de sua plenitude 
seremos capazes de dizer qualquer coisa significativa sobre como um dado sistema econômico influencia os que o constituem, mantém ou superam. E, naturalmente, se isso é verdadeiro para o campesinato ou o proletariado, é certamente verdadeiro para a burguesia, a pequena burguesia e mesmo o lumpemproletariado. ${ }^{26}$ Excluir a experiência dos agentes humanos da análise das relações de classe é fazer a teoria engolir seu próprio rabo.

Uma segunda razão para colocar a experiência dos agentes humanos no centro da análise diz respeito ao próprio conceito de classe. Tudo bem identificar uma coleção de indivíduos que ocupam uma posição comparável em relação aos meios de produção - uma classe em si. Mas, e se tais determinações objetivas, estruturais, encontram pouco eco na consciência e na atividade significativa dos assim identificados? ${ }^{27}$. Ao invés de simplesmente supor uma correspondência unívoca entre a estrutura "objetiva” e a consciência da classe, não seria muito preferível entender como essas estruturas são apreendidas por atores humanos de carne e osso? A classe, afinal de contas, não exaure o espaço explicativo total das ações sociais. Em nenhum outro lugar isso é mais verdadeiro do que na aldeia camponesa, onde classe pode competir com laços de parentesco, vizinhança, facção, e ritual, como focos de identidade e solidariedade humana. Para além do plano da aldeia, pode competir também com etnicidade, grupo linguístico, religião, e região, como focos de lealdade. Classe pode também ser aplicável a algumas situações, mas não a outras; pode ser reforçada ou cruzada por outros laços; pode ser muito mais importante para a experiência de uns do que de outros. Os que estão tentados a descartar como "falsa consciência" todos os princípios de ação humana que competem com a identidade de classe, e a esperar pela "determinação em última instância", de Althusser, provavelmente esperarão em vão. Nesse ínterim, a desordenada realidade de múltiplas identidades continuará a ser a experiência a partir da qual se orientam as relações sociais. Nem camponeses nem proletários deduzem suas identidades direta e somente do modo de produção, e quanto mais cedo tratarmos da experiência concreta da classe tal como ela é vivida, mais cedo apreciaremos tanto os obstáculos quanto as possibilidades para a formação de classe.

\footnotetext{
${ }^{26}$ É também verdadeiro para o padrão regular de atividades humanas que chamamos de instituições. Por exemplo - notem bem, estruturalistas - o Estado.

27 Ver a persuasiva argumentação nesse sentido desenvolvida por Brow (1981).
} 
Outra justificação para uma análise minuciosa das relações de classe é a de que na aldeia, e não apenas nela, as classes se movem sob aparências estranhas e enganosas. Não são apreendidas como conceitos abstratos, fantasmagóricos, mas na forma bastante humana de indivíduos e grupos específicos, de conflitos e lutas específicos. Piven e Cloward captam a especificidade dessa experiência no tocante à classe trabalhadora:

Em primeiro lugar, as pessoas sofrem privação e opressão em um contexto concreto, não como o produto final de processos amplos e abstratos, e é a experiência concreta que molda seu descontentamento em queixas específicas voltadas para alvos específicos. Os trabalhadores vivenciam a fábrica, o ritmo veloz da linha de montagem, o capataz, os espias, os guardas, o proprietário, e o cheque do pagamento. Eles não vivenciam o capitalismo monopolista. (PIVEN e CLOWARD, 1977, p. 20; ênfases minhas)

Da mesma forma, o camponês malaio vivencia preços crescentes no arrendamento da terra, proprietários mesquinhos, taxas de juros ruinosas cobradas pelos emprestadores de dinheiro, colheitadeiras mecânicas que os substituem, e pequenos burocratas que os tratam de maneira indigna. Ele não vivencia o nexo monetário ou a pirâmide capitalista das finanças que faz daqueles donos de terras, proprietários de colheitadeiras, emprestadores de dinheiro e burocratas apenas a penúltima articulação em um complexo processo. Não é de admirar, portanto, que a linguagem de classe na aldeia ostente as marcas de nascença de sua origem distinta. Os aldeões não chamam Pak Haji Kadir de agente do capital financeiro; eles o chamam Kadir Ceti porque foi através da casta Chettiar de emprestadores de dinheiro - que dominou o crédito rural de aproximadamente 1910 até a 2a Guerra Mundial - que o camponês malaio viveu a experiência do capital financeiro. $\mathrm{O}$ fato de a palavra Chettiar ter também conotações similares para milhões de camponeses no Vietnã e em Miamar constitui um tributo à homogeneização da experiência que a penetração capitalista no sudeste da Ásia trouxe em sua esteira. Nem se trata simplesmente de uma questão de reconhecer um mascaramento e de revelar a relação real subjacente, pois o mascaramento, a metáfora, é parte da relação real. Historicamente, a experiência dos malaios com respeito ao emprestador de dinheiro foi a de vê-lo como emprestador de dinheiro $e$ chettiar - isto é, como estrangeiro e não-muçulmano. Similarmente, o malaio vê o lojista e o comprador de arroz não apenas como um 
credor e um negociante atacadista, mas como pessoas de outra raça e outra religião. Desse modo, tal como vivido, o conceito de classe é quase sempre algo como uma liga composta por metais básicos; suas propriedades concretas, seus usos, são os da mistura e não os dos metais puros que ela contém. $\mathrm{Ou}$ as assumimos como as encontramos ou abandonamos inteiramente $\mathrm{o}$ estudo empírico das classes.

Não se deve deplorar o fato de o conceito vivenciado de classe encontrar-se incrustrado em uma história específica de relações sociais. É essa radicação da experiência que lhe dá seu poder e significado. Quando a experiência é amplamente compartilhada, os símbolos que corporificam as relações de classe podem vir a ter um poder evocativo extraordinário. Pode-se imaginar, nesse contexto, como as queixas individuais tornam-se queixas coletivas e como as queixas coletivas podem assumir o caráter de um mito de base classista ligado, como sempre, à experiência local. Assim, um determinado camponês pode ser arrendatário de um proprietário rural que é visto por ele como particularmente opressor. Ele pode resmungar; pode mesmo ter fantasias sobre dizer ao proprietário o que pensa dele, ou ainda ter pensamentos mais sombrios de provocar um incêndio ou de praticar um homicídio. Se se trata de uma queixa isolada, pessoal, o caso provavelmente se esgota aí, na fantasia. Se, entretanto, muitos arrendatários se encontram no mesmo barco, seja por compartilharem o mesmo proprietário arrendador, seja porque seus arrendadores os tratam de maneira semelhante, surge aí a base para uma queixa coletiva, uma fantasia coletiva e mesmo ações coletivas. É então provável que os camponeses intercambiem suas histórias sobre maus arrendadores e, como alguns provavelmente são mais notórios que outros, tornam-se o foco de histórias elaboradas, o repositório de queixas coletivas de grande parte da comunidade contra a condição de arrendador em geral. Em consequência, temos a lenda de Haji Broom, que se tornou uma espécie de abreviatura metafórica para o arrendamento em larga escala na região. Do mesmo modo, temos poemas sobre Haji Kedibut, os quais não são tanto histórias sobre indivíduos, mas símbolos de toda uma classe de proprietários arrendadores.

Se alguma vez tivesse havido (e não houve) um movimento de rebelião em larga escala contra os proprietários arrendadores em Kedah, podemos estar certos de que algo do espírito daquelas lendas teria se refletido na ação. O caminho já estava simbolicamente preparado. Mas o ponto central a ser enfatizado é simplesmente que o conceito de classe, se é para ser encontrado 
de alguma forma, deve sê-lo codificado na experiência concreta compartilhada, que reflete tanto o material cultural como os dados históricos de seus portadores. No Ocidente, o conceito de alimento é mais frequentemente expresso pelo pão. Na maior parte da Ásia, pelo arroz. ${ }^{28}$ Nos Estados Unidos, o nome Rockefeller, com todas as suas conotações históricas, pode ser uma representação sucinta para capitalista; o equivalente para o mau arrendador em Sedaka é Haji Broom, com todas as conotações históricas desse nome.

Por todas essas razões, o estudo das relações de classe em Sedaka, como alhures, precisa necessariamente ser tanto um estudo de significado e experiência como de comportamento estritamente considerado. Nenhum outro procedimento é possível, na medida em que o comportamento nunca é autoexplicativo. Para ilustrar o problema, não é preciso mencionar mais do que o famoso exemplo de um rápido movimento de fechar e abrir as pálpebras de um só olho, utilizado por Gilbert Ryle e mais elaborado por Clifford Geertz (1973, p. 6-9). ${ }^{29}$ Trata-se de um tique nervoso ou de uma piscadela? A mera observação do ato físico não dá nenhuma pista. Se for uma piscadela, de que tipo de piscadela se trata: conspiratória, ridicularizante, de sedução? Só um conhecimento da cultura, das interpretações compartilhadas pelo ator e seus observadores e parceiros, pode começar a nos dizer alguma coisa; e, mesmo então, precisamos levar em conta possíveis equívocos. Uma coisa é saber que os proprietários de terras elevaram o montante de dinheiro exigido pelo arrendamento da terra para o plantio de arroz; outra coisa é saber o que esse comportamento significa para os que foram por ele afetados. Talvez, apenas talvez, os arrendatários vejam o aumento do valor do arrendamento como razoável e há muito justificado. Talvez o vejam com opressivo e com o intento de expulsá-los da terra. Talvez a opinião esteja dividida. Só uma investigação sobre a experiência dos arrendatários, sobre o significado que eles atribuem ao evento, pode oferecer-nos a possibilidade de uma resposta. Digo "a possibilidade de uma resposta" porque pode interessar aos arrenda-

28 "O homem não vive só do pão". Mas "pão" pode vir a significar mais do que apenas alimento; pode significar o meio de vida ou o dinheiro, como em "Você pode me emprestar um pouco de pão?". Na sociedade malaia, o provérbio jangan pecah periok nasi orang (Não quebre a vasilha de arroz de alguém) significa "não ponha em risco a fonte de sustento de alguém".

29 Um excelente sumário dessa posição intelectual pode ser encontrada em Bernstein (1978, p. 173-236). Como observa Bernstein, "Essas descrições, significados e interpretações intencionais não são estados de espírito meramente subjetivos que podem ser correlacionados com o comportamento exterior; são constitutivos das atividades e práticas de nossa vida social e política" (BERNSTEIN, 1978, p. 229-230). 
tários dar uma impressão falsa de sua opinião e, assim, a interpretação pode ser enganosa. Mas, sem essa informação, estamos completamente confusos. Um roubo de grãos, um aparente desprezo, uma dádiva perceptível - sua significação é inacessível a menos que possamos construí-la a partir dos significados que só os atores humanos podem proporcionar. Nesse sentido, nos concentramos no mínimo tanto sobre a experiência do comportamento quanto sobre o próprio comportamento, tanto sobre a história que as pessoas carregam em suas mentes quanto sobre "o fluxo dos eventos" (GEERTZ, 1980, p. 175), tanto sobre como a classe é percebida e entendida como nas "relações objetivas de classe".

Por certo, o enfoque aqui adotado se apoia fortemente no que se conhece como fenomenologia ou etnometodologia. ${ }^{30}$ Contudo não está confinado a esse enfoque, pois é apenas ligeiramente mais verdadeiro as pessoas falarem por si próprias do que o comportamento falar por si mesmo. A pura fenomenologia tem suas próprias armadilhas. Parte considerável do comportamento, incluindo o discurso, é automática e irrefletida, baseada em entendimentos que raramente ascendem ao nível da consciência, se é que o fazem. Um observador cuidadoso precisa oferecer uma interpretação desse comportamento que seja mais do que uma simples repetição do conhecimento de "senso comum" dos participantes. Como interpretação, ela precisa ser julgada pelos padrões de sua lógica, sua economia e sua consistência com outros fatos sociais conhecidos. Os agentes humanos podem também fornecer relatos contraditórios sobre seu próprio comportamento, ou podem querer esconder do observador, ou uns dos outros, sua compreensão a respeito. Por conseguinte, os mesmos padrões de interpretação são aplicáveis, conquanto o terreno seja reconhecidamente traiçoeiro. Além disso, em qualquer situação simplesmente existem fatores que iluminam a ação dos agentes humanos, mas dos quais dificilmente se pode esperar que estes tenham consciência. Uma crise creditícia internacional, mudanças na demanda mundial por grãos, uma luta faccional silenciosa no ministério afetando a política agrária, pequenas alterações na constituição genética das sementes, cada uma dessas coisas pode ter um decidido impacto sobre as relações sociais locais, tenham ou não os atores envolvidos conhecimento delas. Tal conhecimento é o que um observador externo pode muitas vezes acrescentar como um

30 Ver, por exemplo, Turner (1974). 
suplemento, não como substituto, à descrição da situação fornecida pelos próprios agentes humanos, pois, por mais parcial e mesmo equivocada a realidade vivenciada pelos agentes humanos, é essa realidade vivenciada que proporciona a base para sua compreensão e sua ação. Finalmente, não existe tal coisa como uma descrição completa da realidade vivenciada. Não há "uma transcrição verbal completa da experiência consciente" (DUNN, 1979, p. 160). A completude da transcrição é limitada tanto pelo interesse empírico e analítico do transcritor - neste caso, as relações de classe interpretadas de maneira ampla - como pelos limites práticos de tempo e espaço.

O que se busca fazer aqui é, portanto, uma descrição plausível das relações de classe em Sedaka, baseada o quanto possível nas evidências, experiências e descrições de ação oferecidas pelos próprios participantes. Em numerosos pontos, suplementei essa descrição com minhas próprias interpretações, pois estou muito consciente de como a ideologia, a racionalização do interesse pessoal, as táticas sociais cotidianas, ou mesmo a polidez, podem afetar o relato de um participante. Mas espero não ter substituído a descrição deles pela minha. Pelo contrário, procurei validar minha interpretação mostrando como ela "remove anomalias, ou acrescenta informações, na melhor descrição que o participante é capaz de oferecer”. Pois, como afirma Dunn,

O que particularmente não podemos fazer é afirmar que sabemos que o entendemos, ou que compreendemos sua ação, melhor do que ele próprio, sem ter acesso à melhor descrição que ele seja capaz de dar (...). O critério probatório para a validade de uma descrição ou interpretação de uma ação é a economia e a precisão com que ela lida com o texto completo da descrição feita pelo agente. (DUNN, 1979)

\section{Referências bibliográficas}

ADAS, Michael. 1981. "From avoidance to confrontation: peasant protest in precolonial and colonial Southeast Asia". Comparative Studies in Society and History, v. 23, n. 2 p. 217-247.

BERNSTEIN, Richard J. 1978. The restructuring of social and political theory. Filadelfia: University of Pennsylvania Press.

BROW, James. 1981. "Some problems in the analysis of agrarian classes in South Asia”. Peasant Studies, v. 9, n. 1, p. 15-33.

COBB, Richard C. 1970. The police and the people: French popular protest, 1789-1820. Oxford: Clarendon. 
DUMONT, Louis. 1970. Homo hierarchicus. London: Weidenfeld \& Nicholson.

DUNN, John. 1979. "Practising history and social science on 'realist' assumptions”. In: HOOKWAY, C. \& PETTIT, P. (orgs.). Action and interpretation: studies in the philosophy of the social sciences. Cambridge: Cambridge University Press.

GEERTZ, Clifford. 1973. The interpretation of cultures. New York: Basic. .1980. "Blurred genres: the refiguration of social thought". American Scholar, v. 49, n. 2, p. 165-179.

GHEE, Lim Teck. 1977. Peasants and their agricultural economy in colonial Malaya, 1874-1941. Kuala Lumpur: Oxford University Press.

GRAMSCI, Antonio. 1971. Selections from the prison notebooks. Trad. e org. Quinten Hoare e Geoffrey Nowell Smith. London: Lawrence \& Wishart. HARASZTI, Miklós. 1978. A worker in a worker's state. Trad. Michael Wright. New York: Universe.

HARPER, Edward B. 1968. "Social consequences of an unsuccessful low caste movement”. In: SILVERBERG, James (org.). Social mobility in the caste system in India: an interdisciplinary symposium. The Hague: Mouton. HAY, Douglas \& THOMPSON, E. P. 1975. In: HAY, Douglas; LINEBAUGH, Peter; RULE, John G.; THOMPSON, Edward P. \& WINSLOW, Cal (eds.). Albion's fatal tree: crime and society in eighteenth-century England. New York: Pantheon.

HOBSBAWM, Eric J. \& RUDÉ, George. 1968. Captain swing. New York: Pantheon.

HOGGART, Richard. 1954. The uses of literacy. London: Chatto \& Windus. HUIZER, Gerrit. 1972. Peasant mobilization and land reform in Indonesia. The Hague: Institute of Social Studies.

HYDEN, Goran. 1980. Beyond Ujamaa in Tanzania. London: Heinemann. LINEBAUGH, Peter. 1976. "Karl Marx, the theft of wood, and working-class composition: a contribution to the current debate". Crime and Social Justice, n. 6, p. 5-16.

LUKACS, Georg. 1971. History and class consciousness: studies in marxist dialectics. Trad. Rodney Livingston. Cambridge, Mass.: MIT Press.

MOORE JR., Barrington. 1966. Social origins of dictatorship and democracy. Boston: Beacon.

NONINI, Donald M.; DIENER, Paul \& ROBKIN, Eugene E. 1979. “Ecolo- 
gy and evolution: population, primitive accumulation, and the malay peasantry" (Mimeografado).

OI, Jean C. 1983. State and peasant in contemporary China: the politics of grain procurement. Tese de doutorado. Michigan: University of Michigan. PAIGE, Jeffrey M. 1975. Agrarian revolution: social movements and export agriculture in the underdeveloped world. New York: Free Press.

PARKIN, Frank. 1971. "Class inequality and meaning systems". Class inequality and political order. New York: Praeger.

PIVEN, Frances Fox \& CLOWARD, Richard A. 1977. Poor people's movements: why they succeed, how they fail. New York: Vintage.

POPKIN, Samuel L. 1979. The rational peasant. Berkeley: University of California Press.

ROGERS, Susan Carol. 1975. "Female forms of power and the myth of male dominance". American Ethnologis, v. 2, n. 4, p. 727-756.

RUDÉ, George. 1964. The crowd in history, 1730-1848. New York: Wiley.

SCOTT, James C. 1976. The moral economy of the peasant. New Haven: Yale University Press.

1977. "Hegemony and the peasantry". Politics and Society, v. 7, n. 3, p. 267-296.

. 1979. "Revolution in the revolution: peasants and commissars". Theory and Society, v. 7, n. 1-2, p. 97-134.

STOLER, Ann Laura. 1985. Capitalism and confrontation in Sumatra's plantation belt, 1870-1979. New Haven: Yale University Press.

THOMPSON, Edward P. 1978. The poverty of theory and other essays. New York: Monthly Review Press.

TURNER, Roy (org.). 1974. Ethnomethodology: selected readings. Harmondsworth: Penguin.

WOLF, Eric R. 1969. Peasant wars of the twentieth century. New York: Harper \& Row.

ZOLA, Emile. 1980. The earth. Trad. Douglas Parmee. Harmondsworth: Penguin.

\section{Resumo}

A partir de sua pesquisa entre camponeses da Malásia, James C. Scott desenvolve o conceito de "resistência cotidiana", expressão da luta prosaica e constante entre os integrantes das classes dominadas e aqueles que deles buscam extrair trabalho, comida, impostos, 
rendas e juros. Ela se expressa na forma de corpo mole, dissimulação, falsa aquiescência, furto, ignorância fingida, calúnia, incêndio ou sabotagem. Assim, a ausência de formas mais visíveis de oposição política, como rebeliões ou greves, não reflete uma "hegemonia" ideológica e a aceitação passiva da ordem estabelecida pelos dominados, e sim circunstâncias - que são mais a regra do que a exceção - em que uma ação aberta e organizada seria demasiado perigosa.

Palavras-chave: resistência cotidiana; dominação; hegemonia.

\section{Abstract}

From his research among Malaysian peasants, James C. Scott develops the concept of "everyday forms of resistance" which express the prosaic and constant struggle between members of the subordinate classes and those who seek to extract labor, food, taxes, rents, and interest from them. Such forms of resistance express themselves in foot dragging, dissimulation, false compliance, pilfering, feigned ignorance, slander, arson, sabotage, and so forth. Hence, the absence of more visible forms of political opposition, as rebellions or strikes, does not reflect an ideological "hegemony" and a passive acceptation of the established order by those subjected to domination. Instead, it reflects circumstances that are rather the rule - in which an open and organized action would be too dangerous.

Key words: everyday resistance; domination; hegemony. 
